\title{
Influence of Adolescence Developmental Changes on Academic Performance of Students in Public Secondary Schools in Nakuru Municipality, Nakuru County
}

\author{
Gicharu, R.N. ${ }^{1}$, Sindabi, A.M. ${ }^{2}$ \\ Egerton University, Department of Psychology, Counselling and Educational Foundation, P.O. Box 536-20115, Egerton, Kenya
}

\begin{abstract}
Adolescence is an important developmental period when the young person lays the foundation for adult life, it is also a very trying time for the adolescent as he experiences both emotional and physical changes that can negatively influence his life. The academic performance of adolescent students in Nakuru municipality has been deteriorating especially among the adolescent students and the purpose of this study was to investigate on whether adolescence developmental changes (emotions, social behaviour and physical growth) could influence the student's academic performance in public secondary schools of Nakuru municipality. The study adapted an ex-post facto research design. Stratified random sampling was used, where form three students in four schools formed the strata and a sample of 375 students were randomly selected. Fifty one teacher counsellors were also purposively selected for this study. A 25-item survey instrument was used where the students were asked to rate each item on a strongly disagree (1) to strongly agree (5) Likert scale. The data was analyzed using descriptive and inferential statistics with the aid of the Statistical Package for the Social Science (SPSS).

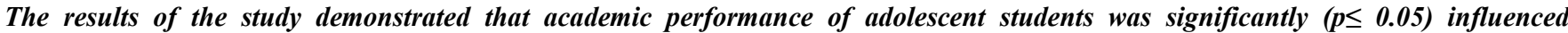
negatively by their emotional behaviour $(\beta=-0.776)$, social behaviour $(\beta=-0.661)$ and physical growth $(\beta=-0.156)$. The findings of this study are significant they may help teacher counsellors and school administrators improve students' academic performance. It is anticipated that the Ministry of Education (MOE) policy makers may develop programmes through which students may be helped to go through adolescence smoothly and be able to achieve their academic goals.
\end{abstract}

Keywords: Academic performance, Adolescence, Adolescent, Emotional behavior, Influence.

\section{Introduction}

An adolescent develops both in sexual functions and abstract thinking processes to independence (American Psychological Association (APA), 2002). Majority of students in secondary schools are adolescents, which is a momentous period of life filled with changes, difficulties and special problems. It is described as period of "storm" and "stress" "turbulent" and "unstable," a time of selfdiscovery and self-assertion (Masese, Nasongo, \& Ngesu, 2012). This is because, adolescents are biologically prone to have more mood swings because of the hormonal changes associated with adolescence, coupled with the fact that their brains are still developing (Murphey, Barry, \& Vaughn, 2013).

The developmental stage of adolescence is the period from 10 to 19 years of age, but may extend up to age 24 (Edberg, 2009). For example, in United States, adolescence starts at ten years of age and ends between the age of eighteen and twenty two years. It is the period between childhood and adulthood that involve biological, cognitive and socioeconomic changes (Santrock, 2010). It is an emotionally intense and often stressful period (Webster, 2013). The journey from childhood to adolescence is very challenging where major changes in physical, cognitive and social development occur (Barnett, 2012).

Adolescence social and emotional behaviour have been issues of concern to many scholars for a long time. Kasomo (2006) describes adolescence as a stage in human life when rapid changes take place. The individuals' physical, mental and social out look undergo revolutionary changes. Due to this growth, an adolescent personality develops in a new dimension. Many parents, teachers, and relatives fail to assess these changes and generally show indifference. This attitude may create many difficulties for the adolescent and his or her concentration in academic work could be affected.

According to Harlock (2006), greater social participation by the adolescents leads to greater social competence. With physical development, an adolescent may not necessarily become socially mature. Therefore his social behaviour should be matched from childhood and corrected when necessary. The adolescent goes through a gradual development process. Positive social participation can only be guided by parents. A child who does not learn proper social behaviour grows selfish during adolescence.

Today's adolescent is different from those of earlier times due to changes in the society and exposure to a variety of intellectual pursuits. Advancement in technology has introduced the adolescents to the use of computers, cellphones and television (Lenhart, Madden, Macgill \& Smith, 2007). Further studies done by Cobb (2004) indicate that adolescents are increasingly engaging in sexual activity and are active by the age of 13-19 years. Adolescents growing up without parental supervision are bound to engage in sexual activity more than those closely monitored (Santrock, 2010).

In Nakuru Municipality just like in other urban areas, adolescents spend most of their time with electronic devices such as computers and televisions either at home or in the 


\section{International Journal of Science and Research (IJSR) \\ ISSN (Online): 2319-7064 \\ Index Copernicus Value (2013): 6.14 | Impact Factor (2015): 6.391}

cyber cafes in town. This may have led to poor social skills since they do not adequately socialize with people. They have little or no time for their school work. Thus, there is a high probability that the social competence of modern day adolescents may be poorer than those of earlier generation (Andrews, 2000). Inability in getting along with teachers and administrators, difficulty adjusting in the school program, classroom misconduct, poor examination grades and lack of school success are associated with delinquency (Steinbery, 2008).

\section{Statement of the Problem}

Academic performance of public secondary schools in Nakuru Municipality has become poor. Students in these schools are in adolescence stage of development and are experiencing physical as well as emotional changes. They want to show that they are sure of themselves and independent. They look for an opportunity to experience sensations more than studying. It is at this particular time that they search for identity and acceptance among the peers. They become exposed to social activities like browsing the internet, taking drugs, alcohol and hanging out with friends. Their behavior may be shaped by these experiences and might have a negative influence on their academic performance. This study sought to determine the influence of adolescence development on students' academic performance in public secondary schools in Nakuru Municipality.

\section{Purpose of the Study}

This study sought to determine the influence of adolescence development on students' academic performance in public secondary schools in Nakuru Municipality.

\section{Objectives of the Study}

The specific objective of the study was to determine whether emotional behaviour of adolescents has an influence on academic performance in public secondary schools in Nakuru Municipality.

\section{Literature Review}

\section{Introduction}

In this chapter, a summary of related literature on adolescents' physiological, social and emotional behaviour changes has been presented. The main topics explored are; meaning of adolescence, adolescent physiological development changes, emotional behaviour, social behaviour, academic performance, guidance and counseling and finally theoretical and conceptual framework of the study.

\section{Adolescence Stages of Development}

According to Kasomo (2006), adolescence is a stage in human life when rapid changes take place. He adds that an individual grows physically, mentally and socially while his personality develops new dimensions. Santrock (2010) asserts that adolescence is the period of transition from childhood to adulthood where young people go through biological, cognitive and psychological changes. Adolescence is accompanied by dramatic physical, cognitive, social, and emotional changes that present both opportunities and challenges for adolescents, families, health professionals, educators, and communities (Cohen, Khurshid \& Aurangzeb, 2012). Socially the young adults develop a sense of identity and self-awareness and they start spending more time with their peers. Early adolescence begins from 10 to 13 years for most adolescents followed by middle adolescence from 13 to 18 years and lastly late adolescence from 18 to 21 years of age (Cohen, 2012). Melgosa (2001) asserts that girls and boys become different when they reach adolescence. Their responsibilities and privileges are different from one stage to another. The adolescent's thoughts, ideas and concepts develop at future life.

\section{Emotional development in Adolescence}

Santrock (2010) defines emotion as a feeling or effect that occurs when a person is in a state or on interaction that is important to the individual. He goes on to say that emotion is characterized by behaviour that expresses the pleasantness or unpleasantness of the state the individual is in. Negative emotions such as sadness are linked with low self-esteem whereas positive emotions such as joy are associated to high self-esteem. Emotional development during adolescence involves establishing a realistic and coherent sense of identity in the context of relating to others and learning to cope with stress and manage emotions (Santrock, 2001).

According to Santrock (2005) adolescence is a time when emotions highs and lows occur more frequently. Adolescents are reported to have extreme emotions associated with increased loneliness, social isolation, disorganized and suicidal thought processes and unusual beliefs that could lead to heavy use of drugs. This significantly interferes with their social and emotional adjustments. However, there are those adolescents who abuse drugs so as to be accepted by peers. Adolescents might sulk a lot when unable to express their feelings with or without provocation. They could even blow up at their parents or siblings, a response that might reflect the defense mechanisms of displacing their feeling onto another person. Leary, M.R (2007) found out that although most students were well adjusted about 20\% developed emotional problems. Some had mood swings, often felt lonely, embarrassed and self conscious. Emotional swings especially in adolescents girls is a reflection of serious problems such as depression. Adolescents have to cope with a new body, and with influences that these changes have on their mood, behaviors and relationships (Bosson, Maggiori, Gygax, \& Gay, 2012).

Santrock (2010) explains that suicide attempts by adolescents have a long history of stress and personal problem originating from childhood issues such as conflict with parents, difficulties in school and increased loneliness during adolescence. He adds that although increased cognitive abilities and awareness of adolescents prepare them to cope more effectively with stress and emotional fluctuations, many adolescents do not effectively manage their emotions. As a result, they may become prone to depression, anger and poor emotional regulation when they fail to cope with these problems. Many adolescents rebel against parental and school authority. Some of them could withdrawal from social relations and make dramatic gestures such as running away from home. Teenage depression could even be triggered by the loss of a loved one, dysfunctional 


\section{International Journal of Science and Research (IJSR) \\ ISSN (Online): 2319-7064 \\ Index Copernicus Value (2013): 6.14 | Impact Factor (2015): 6.391}

family that is threatened by separation and divorce or where family members are in conflict with each other and are not communicating well. In such a scenario the adolescent may be deprived off the emotional support they need. She further explains that unlike adults depressed teenagers may appear to be extremely angry and hyperactive which might be mistaken for normal adolescent emotional behaviour. Kasomo (2006) stipulates that the best way to deal with teenage depression is to communicate with them about their problems on reliable relative or friend could help might be needed. He adds that most adolescents make through these aggravating times and become competent adolescents. Melgosa (2001) suggests that parents must emphasize the positive qualities of their adolescent children to avoid having them join negative groups. When teenagers are satisfied with themselves, they keep their values and beliefs. An emotionally healthy adolescent is one who balances negative and positive emotions, experiences genuine emotions without becoming overwhelmed and expressing them in socially appropriate ways. Educators, teachers and parents are acknowledging the role of emotions and the ability to understand and manage them as determinates to success in life (Andrew, 2000). He further states that adolescence is a critical period for the development of emotional intelligence and emotional competencies that will eventually give an adolescent's life satisfaction and academic achievements.

\section{Social development in Adolescence}

Adolescence signifies a critical and distinctive period in the life cycle, marked by rapid cognitive growth that drastically changes how one understands, communicates and functions within the social world (Moshman, 2011). Santrock (2010) stipulates that adolescents' physical maturation affects their social behaviour. According to Kaplan (1986) adolescence could be a very embarrassing period in the life of a teenager. Girls worry about the size of their breasts and the possibility of getting menstrual blood on their clothes. While boys worry about regular erection and unusual ejaculation. This makes the adolescents anxious and apprehensive when participating in co-curricular activities. These could have a negative influence on the adolescent's academic performance.

Mbiti (1969) explains that rites of passage in African communities introduced the candidate to adult life. They would share in the responsibilities and privileges of the community. This prepared the candidate for the expected social behaviour. Santrock (2010) explains that the purpose of social development is to seek freedom, relations and identity. He further states that the adolescent tries to synthesize the past, present and their future possibilities into accepted self. This is the adolescent search for identity. They have a great desire to be accepted and to identify with current teenage language, music, fashion and all types of entertainment. They try different selves in different situations. The adolescents could be a different person at home, with friends and at school. Such confusion can affect academic performance negatively. Erikson (1969) stipulates that not everyone fully achieves identity. Most adolescents face identity crisis where they explore different possibilities and integrate different parts of themselves. Failure to form cohesive identity beyond adolescence can lead to problem later in life (Kroger, 1996). Girls who have difficulties forming an identity are more likely to experience marital disruptions in mid life than their peers while boys are more likely to remain single and unsatisfied.

Many researchers have established a link between hormone levels and behaviour. Melgosa (2001) explains that boys who exhibit low levels of testosterone and high levels of endostestorene are more likely to manifest behaviour problems. These could range from talking back to adults and questioning authority in almost all domains. Kimmel and Weiner (1995) reveal that the root of anti social behaviour in children and adults is their temperament from infancy where they could have had irregular sleep or restlessness. They add that effective parenting could improve many of these antisocial behaviour.

According to Kasomo (2006) proper socialization of an adolescent is important. When teenagers are not well nurtured socially by their parents, teachers and peers, they lack in qualities such as honesty, courage, kindness and selfesteem. He adds that this could result in maladjusted students who may not attain social maturity. Qureshi (2004) asserts that students who lack constant social stimulation experience intellectual deterioration and impaired problem solving abilities. A study by Soomro and Clarbour (2012) revealed that high social self-esteem is related to higher academic achievement.

\section{Physical development of adolescents}

The most noticeable changes during adolescence involve physical, psychological, sexual growth and development, including the appearance of secondary sexual characteristics and the ability to reproduce (Cohen, 2012). Adolescents are worried by these physical changes and how they are perceived by others. Regardless of the timing of the physical changes that take place during adolescence, this is a period in which physical appearance commonly assumes paramount importance (American Psychological Association, 2002).

\section{Cognitive Development}

Adolescents begin moving from childhood to adulthood due to their cognitive development. The brains begin to process more abstract thoughts especially focused towards selfreflection and self-identity (Barnett, 2012). They endeavor to learn to make good choices and decisions toward their future as responsible nationals. As adolescents develop their understanding of themselves, they become more aware of their emotions and feelings and how these feelings affect their daily lives. This is how they perceive their characteristics and abilities fit with the opportunities that are available to them. Many of the identity issues that begin during adolescence determine the paths an adolescent may take including future college, vocational or career choices, as well as other aspects of their lives.

\section{Parental Role in Adolescents' Academic Performance}

Parents are the first socializing agents in an individual's life. Providing a supportive learning environment at home requires parents' time as much as financial resources (Emeka, Ononga, Owolabi, Ushie 2012). Weiner et al (1995) stipulates that young people usually identify closely with their parents' feelings about school and education. $\mathrm{He}$ explains that parents who value the education process and 


\section{International Journal of Science and Research (IJSR) \\ ISSN (Online): 2319-7064 \\ Index Copernicus Value (2013): 6.14 | Impact Factor (2015): 6.391}

respect the efforts of their children teachers, foster positive attitude towards school and thereby influencing their children academic performance positively. Parents who are warm and accepting tend to have children who are socially competent. Adolescents who have experienced sibling hostility and inconsistent parenting during childhood and early adolescence end up having anti-social behaviour. Kroger (1996) adds that students who bully at school come from homes where they were bullied or canned. Whereas those students who look happy, relaxed and are well behaved were brought up without a lot of strictness and most of them succeed academically.

\section{Academic Performance among Adolescents}

Weiner et al (1995) explains that being in school and achieving at the level of their ability helps young people feel good about themselves. Those who do poorly or drop out of school develop low self-esteem and may fail to realize their intellectual and occupational potential. He adds that an adolescent's attitude towards school is influenced by peer and parental attitude towards school administration; grades attained and school disciplinary structure. Adolescents whose parents have unrealistic high expectations for their academics or social achievements may become truants or drop out of school all together (Nancy, 2004). Adolescents often suffer from mild mental disorders

Developing social and emotional capabilities supports the achievement of positive life outcomes, including educational attainment, employment and health (McNeil, Reeder \& Rich, 2012). Skills such as flexibility, communication, and negotiation enhance employability. Santrock (2010) reveals that adolescents who are unable to establish positive identity may perform poorly in schools since they lack successful adult with whom to identify with. Such adolescents develop negative identity by taking up antisocial role in the society that nevertheless provide them with a sense of belonging.

\section{Guidance and Counselling for Adolescents}

Mangal (2007) cites that teacher counsellors, psychologists and parents have a duty to train the adolescents on how to integrate thoughts and emotions for proper behaviour. This he suggest could be attained by encouraging the adolescents not to suppress emotions since each feeling is significant as well as striking a balance between rational thoughts and emotions. Melgosa (2001) asserts that could support their children in their studies by devoting time to be with them. Spielberg (2002) supports this view and explains the "peer cluster theory" that young people who are in trouble in school have a tendency to find each other leading to further problems. There is need to counsel them before they get into antisocial behaviour. He further adds that they should be helped to develop social skills for better communication and interpersonal relationship with others.

\section{Conceptual Framework}

Intervening variables
Dependent variables

\begin{tabular}{|c|c|c|}
\hline $\begin{array}{l}\text { Adolescence } \\
\text { Developmental changes } \\
\text { Indicators } \\
\text { - Emotional behaviour- anger, } \\
\text { patience, outbursts, mood swings } \\
\text { - Social- identity crises } \\
\text { - Physical-growth development of } \\
\text { the body, broken voice }\end{array}$ & $\begin{array}{l}\text { - School environment } \\
\text { - Family background } \\
\text { - Parenting styles } \\
\text { - Peer pressure } \\
\text { - Cultural influences }\end{array}$ & $\begin{array}{l}\text { - Academic performance } \\
\text { (measured in grades) } \\
\text { - Class attendance } \\
\text { - Self-concept } \\
\text { - Discipline }\end{array}$ \\
\hline
\end{tabular}

Figure 1: Influence of Adolescence on Academic Performance of Students in Public Secondary Schools in Nakuru Municipality in Nakuru County.

\section{Research Methodology}

The study adopted the ex-post facto research design. Kathuri and Pals (1993) defined ex-post facto research as a systematic empirical inquiry in which the researcher does not have direct control of independent variables because their manifestation has already occurred or because they cannot be manipulated. This design is appropriate for this study because the manifestation of independent variables, that is emotion, social behaviour and physical changes, have already occurred without any manipulation, it is therefore appropriate to use this research design. This design is ideal as it enables an in-depth study of the relevant variables to be made in order to establish existing conditions in the schools. Studies that are concerned with what people think and what they do, and different types of educational fact finding, can utilize this research design (Frankel and Wallen, 1993). Mugenda and Mugenda (1999) argue that the method is often used because it does not permit experimental manipulation of the variables. This design is thus appropriate in determining influence of adolescence on academic performance of students in public secondary schools in Nakuru Municipality.

\section{Population of the Study}

The target population totaled 14,832 form three secondary school students in 45 public secondary schools within the Nakuru municipality and 60 teacher counselors who are involved in guidance and counselling in public secondary schools in Nakuru Municipality. The accessible population was 375 students and 51 teacher counsellors. The sample comprised both male and female students and teachers. Form three students were found to be the suitable choice because most of them were in mid adolescence and were likely to exhibit adolescent's psychosocial, cognitive and emotional behaviour. 


\section{International Journal of Science and Research (IJSR) \\ ISSN (Online): 2319-7064}

Index Copernicus Value (2013): 6.14 | Impact Factor (2015): 6.391

Sampling Procedure and Sample Size

The Sample of 375 students who formed the main respondents were selected using stratified random sampling (where the form three class in the selected school was picked to form the strata). The sample of 51 teacher counselors were purposively selected (where a teacher counselor in each of the 45 schools was picked). The number of samples required was calculated using the formula described by Krejcie and Morgan (1970) as follows:

$$
\mathrm{S}=\frac{x^{2} N P(1-\rho)}{d^{2}(n-1)+x^{2} p(1-p)}
$$

Where;

$S=$ The required Sample Size

$N=$ The given population within the study area $(14,832)$

$P=$ Population proportion of 0.50

$d=$ Degree of accuracy-Amount of error tolerated in this study- 0.50

$X^{2}=$ Table value of Chi-square for one degree of freedom at a confidence level of 0.95 (which is 3.841)

Based on the above calculation a sample size of 375 students and 51 teacher counsellors was determined.

\section{Results and Discussion}

\section{Characteristics of the Student Respondents}

The characteristics of the student respondents interviewed have been organized in to two categories namely age and gender of the respondents.

\section{Age of Respondents}

The age of respondents is a factor considered important to this study. This is due to the fact that adolescence affects individuals between the ages of 15 and 20. The students were asked to state their age and the results are given in Table 2 .

Table 2: Age of the respondents

\begin{tabular}{|c|c|c|}
\hline Age in years & Frequency & Percent \\
\hline 15 & 15 & 4.0 \\
\hline 16 & 105 & 28.0 \\
\hline 17 & 167 & 44.5 \\
\hline 18 & 64 & 17.1 \\
\hline 19 & 17 & 4.5 \\
\hline 20 & 7 & 1.9 \\
\hline Total & 375 & 100.0 \\
\hline
\end{tabular}

Mean 16.95 \pm 0.51 , median 17, mode 17, std dev 0.986, minimum 15, and maximum 20

The majority of the respondents were between the age of 16 and 18 years, with only $6.4 \%$ of them being above 18 years. The youngest respondent was aged 15 years, while the oldest was aged 20 years. The mean age was 17 years with a standard deviation of 0.986 , meaning that there was a small variation in the age of the respondents. These findings reveal that majority of the respondents were in the age bracket when the adolescent problems are manifested.

\section{Gender of the student respondents}

The study aimed at determining whether there existed gender differences that were related to adolescent problems. The respondent's gender was recorded and their responses are given in Table 3 .

Table 3: Gender of the Student Respondents

\begin{tabular}{|l|c|c|}
\hline Gender & Frequency & Percent \\
\hline Male & 210 & 56.0 \\
\hline Female & 165 & 44.0 \\
\hline Total & 375 & 100.0 \\
\hline
\end{tabular}

From the data gathered majority of the respondents $(56 \%)$ were male, while the females formed $44 \%$ of the sample. The differences in the number of the male and female students was line with the proportions that existed in the student population in the municipality. The male population of the boys in the municipality schools was 8,232 (55.5\%), while the female was $6,600(44.5 \%)$.

\section{Summary, Conclusion and Recommendations}

\section{Summary of the Study}

This research was undertaken to establish the effect of three factors associated with adolescent students (emotions, social behaviour and physical growth) and the role of counselling on the academic performance of secondary students in Nakuru municipality. The study interviewed a randomly selected sample of 375 form three secondary school students and 51 teacher counsellors who were purposively selected. The results of the study demonstrated that the academic performance of adolescent students was significantly ( $p \leq$ 0.05 ) influenced negatively by adolescent emotional behaviour, social behaviour, and physical growth.

\section{Conclusions}

Based on the findings of the study, the following conclusions were made:

1) In the Nakuru municipality secondary schools the boys formed the largest portion of the student population (56 $\%)$ compared to the girls.

2) The teacher counsellors in secondary schools within the Nakuru municipality were mainly men $(52.9 \%)$. The majority of teacher counsellors $(70.6 \%)$ had degrees, but only $41.2 \%$ were trained in counselling.

3) The academic performance of the secondary students in the Nakuru municipality averaged 7.8 (on a scale of 1 to 12). The majority of the students (77.1\%) were performing below the average score. The male students had significant $(\mathrm{p} \leq 0.05)$ higher mean scores than the female students.

4) The emotional behaviour of the adolescent students in Nakuru municipality was found to be within the medium range (a score of 15 on a scale of 5 to 30 ). The academic performance of adolescent students was significantly $(\mathrm{p} \leq 0.05)$ negatively affected by the emotional behaviour of the adolescent students.

5) The social behaviour of adolescents in Nakuru municipality secondary schools was rated at 15.8 on a scale of 1 to 30 . The academic performance of the adolescent students was significantly $(p \leq 0.05)$ 


\section{International Journal of Science and Research (IJSR) \\ ISSN (Online): 2319-7064 \\ Index Copernicus Value (2013): 6.14 | Impact Factor (2015): 6.391}

negatively affected by the social behaviour of the adolescent students.

\section{Recommendations}

The following can be done to enhance the academic performance of the adolescent students in secondary schools within the Nakuru municipality:

1) Use of professionally trained teacher counsellors with experience to assist the adolescent students with the problems they are undergoing

2) The emotional behaviour had the highest influence on the academic performance and if the schools put more emphasis on it there may be higher returns

\section{Acknowledgement}

I highly acknowledge my supervisor Prof. Sindambi for his unfailing encouragement and support during my research. His personal commitment has contributed in making this research journal what it is. His valuable feedback and professional advice received from him was very instrumental towards the completion of this work. I am also grateful to the principals, teachers and students of Nakuru Municipality, public schools especially those who were involved in the study for their unfailing assistance and understanding. Finally, my gratitude goes to all others who in one way or another contributed to the completion of this research

\section{References}

[1] Anand, F., Goheer, A., Dieter, R. H., Kaplan, A.D., Kerstetter, K., Kirk, A.L.M., Liu S., Arul, M. T. \& Yeh, T.(2004). Promoting Academic Achievement and Motivation: A Discussion \& Contemporary Issues Based Approach. Retrieved on 7-4-2013 from http://www. gemstone. umd.edu/ teams/documents/final thesis.pdf

[2] Andrew, D.W. (2000). Nature of adolescence risk taking www/academic.com/meta/p/26407

[3] Barnett, R.V. (2012). Helping teens answer the question. "Who am I?" Cognitive development in adolescents. University of Florida. Retrieved on 14-42013 from http://www. edis.ifas.ufl. edu/pdffiles/FY/FY76900.pdf.

[4] Bosson, M., Maggiori, C., Gygax, P.M., \& Gay, C. (2012). Smoking and adolescence: Exploring tobacco consumption and related attitudes in three different age groups in Switzerland. Journal of Youth Studies, 15, 225-240. Retrieved on 7-4-2013 from http://www.unifr.ch/

psycho/site/assets/files/.../Bosson_etal_preprint.pdf.

[5] Cohen, M. I. (2012). Adolescence: 11-21 years. Retrieved on 13-4-2013 from http:/www.bright futures. org/ bf2/pdf/pdf/AD.pdf

[6] Douglas, C. Kimmel, Irring, B. Weiner (1995). Adolescence: A Developmental Transition. New York/ADAGAP Paris.

[7] Dictionary.com (2014). Definition of Influence. Retrieved, from http://dictionary.reference.com/browse/influence on March 14, 2014

[8] Edberg, M., (2009). Part 3: Revised Draft UNICEF/LAC core indicators for MICS4 (and beyond) with rationale and sample module. Retrieved on 7-4-2013 from Retrieved from http://www.unicef.org/lac/core_indicators_part_3_mic s.pdf

[9] Khurshid, F. \& Aurangzeb, W. (2012). Teaching styles \& adolescents' psychosocial development. Global. Journal of human social science, Linguistics \& Education (12) 10 Ver 1, Global Journals Inc. (USA). ISSN: 2249-460x. Retrieved on 21-4-2013 from https:/globaljournals.org/GJHSS Volume12/4Teaching-Styles-and-Adolescents-PsychosocialDevelopment.pdf

[10] KIE. (2004). The Guiding and Counseling Teachers Hand book. KIE Nairobi.

[11] Kathuri, N. J. \& Pals, D. N. (1993). Introduction to Educational Research. Njoro: Egerton University Media Press.

[12] Kothari, C.R. (2008). Research Methodology methods and techniques. Mumbai: New Age International (P) Limited.

[13] Krejcie, R.V., \& Morgan, D.W., (1970). Determining Sample Size for Research Activities. Educational and Psychological Measurement. 30, 607-610.

[14] Leary, M.R. (2007). Motivation and Emotional Aspects of Self. Annual Reviews of Psychology (Vol. 158).

[15] Webster (2013) Definition of emotional. Retrieved on 9-4-2013 from http://www. merriamwebster.com/dictionary/adolescence

[16] Webster (2013) Definition of social. Retrieved on 214-2013 from http://www.merriamwebster.com/dictionary/social

[17] Westwood P. (2004). Learning and Learning Difficulties: A handbook for teachers. ACER Press http://www.vnseameo.org/.../learning\%20and\%20lear ning\%20Difficulties (ISBN 0846317697. ) 